Classification

Physics Abstracts

$61.16 \mathrm{Bg}-68.35 \mathrm{Dv}$

\title{
Structure and chemistry of grain boundaries in yttria doped aluminas
}

\author{
Danièle Bouchet $\left({ }^{1}\right)$, Frédéric Dupau $\left({ }^{2}\right)$ and Sylvie Lartigue-Korinek $\left({ }^{3}\right)$
}

(1) Laboratoire de Physique des Solides, UA CNRS 002, Bât. 510, Université Paris Sud, 91405 Orsay, France

( ${ }^{2}$ ETCA, CREA, PS 10, 16 bis Av. Prieur de la Côte d'or, 94114 Arcueil, France

$\left({ }^{3}\right)$ Laboratoire de Métallurgie Structurale, UA CNRS 1107, Bât. 413, Université Paris Sud, 91405 Orsay, France

(Received 15 July, 1993; accepted 15 January, 1994)

\begin{abstract}
Résumé. - Nous avons étudié la structure et la chimie des joints de grains de deux alumines, l'une codopée à la magnésie et à l'yttrium et l'autre dopée uniquement à l'yttrium. Pour les deux matériaux, l'yttrium est ségrégé dans tous les joints sauf un. Léchantillon recuit présente une ségrégation intergranulaire de silicium, généralement plus faible que la ségrégation d'yttrium dans le même joint. Nous avons mis en évidence une relation entre l'orientation du plan de joint et la nature et la quantité d'espèces ségrégées. Les joints dont le plan est parallèle au plan (0112) dans un des grains présentent une ségrégation préférentielle d'yttrium. Le silicium est fortement ségrégé dans les joints parallèles au plan basal (0001). Ceci montre que la force motrice pour les ségrégations fait intervenir les effets de charge et l'interaction élastique. Enfin, nous avons mis en évidence une ségrégation d'yttrium sur les dislocations intergranulaires.
\end{abstract}

\begin{abstract}
The structure and chemistry of grain boundaries (GB's) are investigated by TEM in an alumina codoped with magnesia and yttria and an alumina doped with only yttria. Yttrium is segregated in the two materials at nearly all GB's. A segregation of silicon occurs in the annealed alumina GB's, generally lower than yttrium segregation, in agreement with a driving force energy resulting from elastic interaction. A relationship between the GB plane orientation and the nature and content of segregated species has been evidenced: a preferential segregation of yttrium occurs in GB's whose plane is parallel to the $(01 \overline{1} 2)$ plane in one grain. Silicon is highly segregated at GB's parallel to the basal (0001) plane in one grain, showing that the driving force for segregation of this aliovalent solute also includes charge effects. Finally, a preferential segregation of yttrium occurs on GB dislocations, in agreement with the strengthening effect of yttrium during superplastic deformation of alumina.
\end{abstract}

\section{Introduction.}

Residual impurities and intentionally added dopants play a major role in determining the final microstructure and related properties of polycrystalline sintered alumina. Most of elements present a low limit of solubility in alumina and thus are segregated at grain boundaries (GB's) [1]. Since 
GB's are important in influencing most material properties, it seems worthwhile to investigate the structure and chemistry of grain boundaries. Variations in segregated concentrations of different species at alumina GB's have been reported by AES analyses and attributed to differences in GB structure [2] but no direct relationship between segregation and structure has been established. Let us keep in mind that this relationship is two-fold, depending on thermomechanical treatments. On one hand, the segregated species can modify the GB crystallographic parameters; on the other hand, the GB structure itself may determine the GB content in segregated species.

The segregation-structure relation has been widely investigated in metallic materials but it is far from being well established and it has been found to be very complex with evolution of investigation techniques [3]. The first Auger experiments showed that segregation occurs preferentially in general GB's rather than in special GB's which present an ordered structure according to Bollman's formalism [4]; in other words, they found correlation between the three dimensional (3D) coincidence and the segregation. More recent studies on polycrystalline metallic materials, by conventional transmission electron microscopy, emphasize the predominant influence of the orientation of the GB plane on the segregation behavior, on the basis of a planar atomic density criterion, whatever the 3D coincidence parameter $\Sigma$ is [5]. At this stage, it seems useful to discuss the concept of speciality: in previous studies, so-called special GB's were close to a coincidence orientation relationship, the allowed angular deviation from the exact coincidence orientation being less than a limit that depends on $\Sigma[6]$; the orientation of the GB plane is not considered. It is recognized that there is no simple correlation between the existence of a $3 \mathrm{D}$ coincidence and a special property of a GB, i.e., there is no absolute criterion of speciality; however this geometrical criterion permits to make a first selection of GB's that are likely to present special properties, and has been found to account for particular GB mechanical properties [7,8]. This criterion will be retained in the present work as a starting point to precise the distribution of GB's in alumina polycrystals, but it does not assume necessarily a special GB segregation. Recent HREM investigations on the atomic structure of near coincidence bicrystal GB's as a function of segregated impurities showed that the complex morphology of the GB plane must be taken into account: most often the plane of a GB slightly deviated from coincidence, and thus one GB previously considered as special, is non rectilinear and it is composed of sequences of perfect structural units separated by defects at the nanometer scale, making the segregation - structure relation very complex [9].

In the case of ionic crystals, there are very few experimental investigations. For example, in $\mathrm{MgO}$, calcium and silicon segregations have been found to be reduced by half in coincidence twist GB's, in comparison with a general GB [10]. However, the given characteristics of the general GB let suppose a random orientation of its GB plane and consequently a role of the GB plane density on the level of segregation cannot be ruled out in this study.

First of all, it is worthwhile to recall the main microstructural features of yttria doped aluminas.

\section{Role of yttrium on alumina microstructure and properties.}

In alumina, the particular case of yttrium is interesting: this element is strongly segregated in GB's [1,11] and it leads to striking modifications of the creep behaviour of $\mathrm{Mg}$ - doped alumina. Owing to the fine grain size resulting from $\mathrm{MgO}$ addition, this material displays a structural superplasticity where the predominant process is a diffusion controlled GB sliding [12-15]. This may be interpreted on the basis of an intergranular dislocation creep model [7,16]. Codoping with yttrium leads to a sharp decrease in the initial deformation rate [13]; it has been suggested that yttrium modifies the role of GB's as sources and sinks for lattice dislocations [17]; in particular, it has a strengthening effect towards the accommodation mechanisms of intergranular dislocations, resulting in stress concentrations in GB's; stress relaxation occurs by emission of dislocations in the bulk and by basal twinning, as observed by Transmission Electron Microscopy [18]. The plas- 
tic deformation of grains includes extended stacking faults along the basal plane, emitted from the grain boundary and bordered by partial dislocations, suggesting that yttrium must favor glide dissociation rather than climb dissociation usually observed in alumina [19].

Thus, we have developped a microstructural study of intergranular segregation of yttrium with two aims: on one hand to more thoroughly understand yttrium effect on the creep deformation of alumina, on the other hand to define the parameters of the relationship between GB structure and segregation. The solubility limit of yttrium in alumina is very low [20]. It has been shown in fine grained alumina doped with $500 \mathrm{ppm} \mathrm{Y}_{2} \mathrm{O}_{3}$ that yttrium GB concentration increases linearly with increasing grain size up to $2.6 \mu \mathrm{m}$ for which value a saturation level is reached [11]. A precipitation of yttrium garnet takes place at triple points and GB yttrium concentration remains constant for larger grain sizes.

The present paper concerns TEM investigations of GB crystallographical parameters and chemical characteristics in two different alumina specimens: the first one is a fine grained MgO-doped alumina that has been deformed in compression; in this sample, the segregation phenomena are probably characteristic of a nonequilibrium state; this analysis could help us to understand the role of yttrium during creep. With the aim to more accurately investigate the relationship between GB structure and segregation, we have studied another alumina doped with only yttrium and annealed at high temperature so as to obtain an equilibrium state of GB structure and segregation.

\section{Experimental.}

3.1 MATERIALS. - The first specimen is a fine grained alumina (called CMgY) which has been doped with nominal concentrations of $500 \mathrm{ppm} \mathrm{MgO}$ and $500 \mathrm{ppm} \mathrm{Y}_{2} \mathrm{O}_{3}$; it has been hot pressed at $1450{ }^{\circ} \mathrm{C}$ under $45 \mathrm{MPa}$ and deformed by compression under $20 \mathrm{MPa}$ at the same temperature. The final grain size is $\mathrm{d}=2 \mu \mathrm{m}$.

The second sample (called BYR) is doped with 500 ppm $\mathrm{Y}_{2} \mathrm{O}_{3}$; it has been hot pressed at $1550{ }^{\circ} \mathrm{C}$ under $45 \mathrm{MPa}$ and annealed at $1500^{\circ} \mathrm{C}$ during 12 hours. The final grain size is heterogeneous and varies from 2 to $50 \mu \mathrm{m}$.

The residual impurity contents are reported in table I. Unexpectedly, the second alumina contains 260 ppm of silicon which have probably been introduced during annealing process. Indeed, silicon contamination can arise from evaporation of the glassy phase probably present at the GB's of the commercial polycrystalline alumina furnace tube.

Table I. - Impurity contents of aluminas "CMgY" and "BYR" (concentrations in ppm weight \%).

\begin{tabular}{|c|c|c|c|c|c|}
\hline specimen & Ca & Fe & N a & S i & K \\
\hline \hline CMgY & 5 & 9 & 28 & 54 & 50 \\
\hline BYR & 1 & 7 & 10 & 260 & 45 \\
\hline
\end{tabular}

3.2 GRAIN BOUNDARY ANALYSIS. - Foils are thinned by ion milling at $5 \mathrm{kV}$ operating voltage. The experimental purpose is to characterize the structure and the chemistry of a same GB.

3.2.1 Grain boundary structure. - The crystallographical investigations are performed on a conventional 2000 EX JEOL TEM. All the equivalent relative orientation relationships are determined for each grain boundary, allowing their classification as near coincidence or general GB's on the basis of a geometrical approach of three dimensional and one dimensional coincidence 
models relevant to the rhombohedral symmetry and described in previous papers $[8,16]$. The orientation of the GB plane is also determined.

In addition, in the deformed sample "CMgY" the distribution of GB's has been determined by analysing a high number of adjacent GB's in two regions of the sample.

Some well oriented GB's are observed in HREM mode on a TOPCON ABT 002B operating at $200 \mathrm{kV}$. The spherical aberration coefficient is $0.4 \mathrm{~mm}$, the beam divergence is about $1 \mathrm{mrd}$ and the defocus spread is $8 \mathrm{~nm}$. The images are acquired with a Gatan slow scan CCD camera and treated with the Digital Micrograph software.

3.2.2 Grain boundary chemistry. - The segregations in the "CMgY" sample are analysed by EDXS on a dedicated STEM VG HB 501 microscope equipped with a field emission gun and operating at $100 \mathrm{kV}$. The diameter of the probe is about $1 \mathrm{~nm}$ delivering an intensity of $0.8 \mathrm{nA}$. In order to minimize irradiation damage, we do not use the spot mode but the reduced area mode. The size of the analysed area varies from $3 \mathrm{~nm} \times 4 \mathrm{~nm}$ to the probe size diameter. The chosen analysed GB's are parallel to the electron beam. The EDX analysis is performed with a $10 \mathrm{~mm}^{2}$ $\mathrm{Si}-\mathrm{Li}$ detector with a Be window.

For the "BYR" sample, intergranular segregations were also measured by EDXS on the TOPCON ABT microscope. The probe sizes, used in spot mode, are $5 \mathrm{~nm}(0.6 \mathrm{nA})$ and $2.5 \mathrm{~nm}(0.3$ $\mathrm{nA})$. The detector is a $30 \mathrm{~mm}^{2} \mathrm{Si}-\mathrm{Li}$ diode with an ultra thin window.

Owing to occasional problems of radiation damage and eventual channeling effects along a vertical interface and considering that only comparative values of segregated elements are meaningful for the purpose of this study, it is wiser to express the results, after deconvolution, in terms of area intensity ratios $\left(\mathrm{Si}_{\mathrm{K}} / \mathrm{Al}_{\mathrm{K}}\right.$ and $\left.\mathrm{Y}_{\mathrm{L}} / \mathrm{Al}_{\mathrm{K}}\right)$ in the analysed volume.

\section{Results.}

4.1 MICROSTRUCTURE AND GB DISTRIBUTION. - The microstructure of the fine grained alumina "CMgY" submitted to the compressive creep is equiaxed (Fig. 1), and it contains a relatively high proportion of near coincidence GB's. Indeed, among 23 analysed GB's, seven are near coincidence GB's including two near CSL GB's, one Low Angle GB and four one dimensional GB's. This distribution is akin to those obtained in previous works on $\mathrm{Mg}$-doped aluminas with similar grain sizes. The orientations of the GB planes are random, i.e. they do not correspond to common planes of the near coincidence description or to dense planes of alumina, as it may be expected from their most often curved profile. Note that the grain size $d$ is slightly lower than the $d$ value for which yttrium is saturated to GB's. Finally, periodic and pseudo-periodic dislocation networks occur in four near coincidence GB's and two general GB's.

The alumina only doped with yttrium "BYR" presents an heterogeneous microstructure and an exaggerated growth of lathlike grains (Fig. 2). As expected from the large grain size, it contains numerous yttrium garnet $\left(\mathrm{Y}_{3} \mathrm{Al}_{5} \mathrm{O}_{12}\right)$ precipitates that are found to be mainly intragranular (Fig. 2). All of the 12 analysed GB's are general. However, for half of them, the GB planes are parallel to a dense plane of alumina in one grain, most often the basal (0001) and the rhombohedral

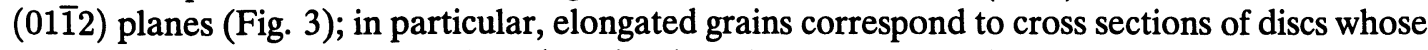
faces are parallel to the basal plane (0001). This microstructure is characteristic of non Mg-doped alumina [16] and has been recently attributed to an effect of codoping of residual impurities [21]. 


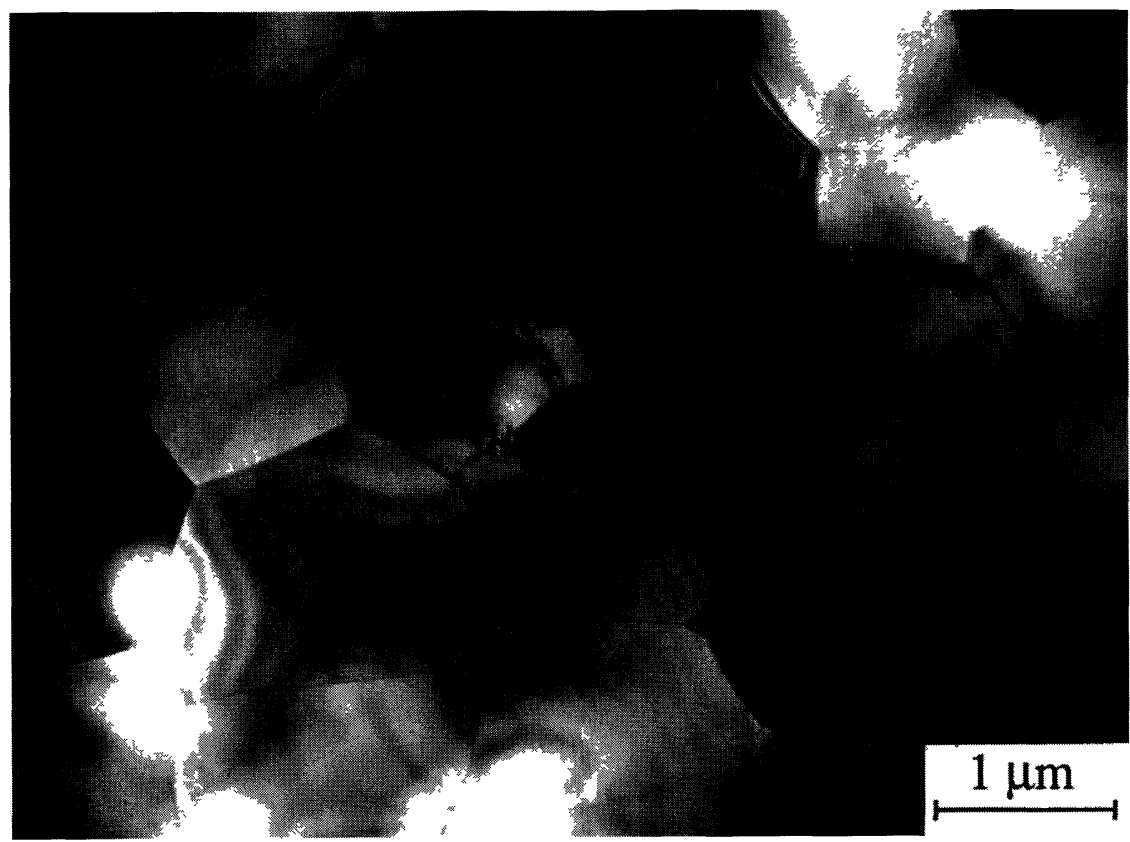

Fig. 1. - Equiaxed microstructure of the fine grained alumina "CMgY".

4.2 GENERAL FEATURES OF INTERGRANULAR SEGREGATION. - The general aspects of GB chemistry of the two studied samples are the followings:

- as expected, yttrium has not been detected in the matrix and is segregated in all GB's of the two materials (except one, see further Sect. 4.3). As for the extent of this segregation, quite large yttrium gradients occur at GB's in the deformed sample, which is in a non equilibrium state. Furthermore, this gradient can be asymmetrical: yttrium spreads over 10 to $12 \mathrm{~nm}$ from one side of the GB, and over about $3 \mathrm{~nm}$ on the other side. This asymmetrical gradient results probably from the grain growth occurring during superplastic deformation of alumina: during their migration, the GB's leave behind them an atmosphere of yttrium atoms.

- in the annealed sample "BYR" which is much closer to the thermodynamical equilibrium state, no yttrium gradients are found, at least in the limit of the $2.5 \mathrm{~nm}$ probe size, i.e. on a $2 \mathrm{~nm}$ GB width.

- some particular regions of the annealed specimen "BYR" are rich in silicon. In these regions, the triple junctions are wetted by an amorphous phase and adjacent GB's contain a cosegregation of silicon and yttrium (see Sect. 4.3).

- calcium has been detected neither in GB's nor in triple points.

4.3 INTERGRANULAR SEGREGATION AND GRAIN BOUNDARY STRUCTURE. - Noticeable variations in the level of both yttrium and silicon segregation from one GB to another one have been found, as usually observed in materials. An important observation is that GB yttrium content is always larger than silicon content in Si-rich areas, except for some particular GB's, as discussed below.

Concerning the relationship between the $3 D$ coincidence and segregation, two results are particularly worthnoting:

- among 26 chemically analysed GB's, only one of them, whose general character has been 


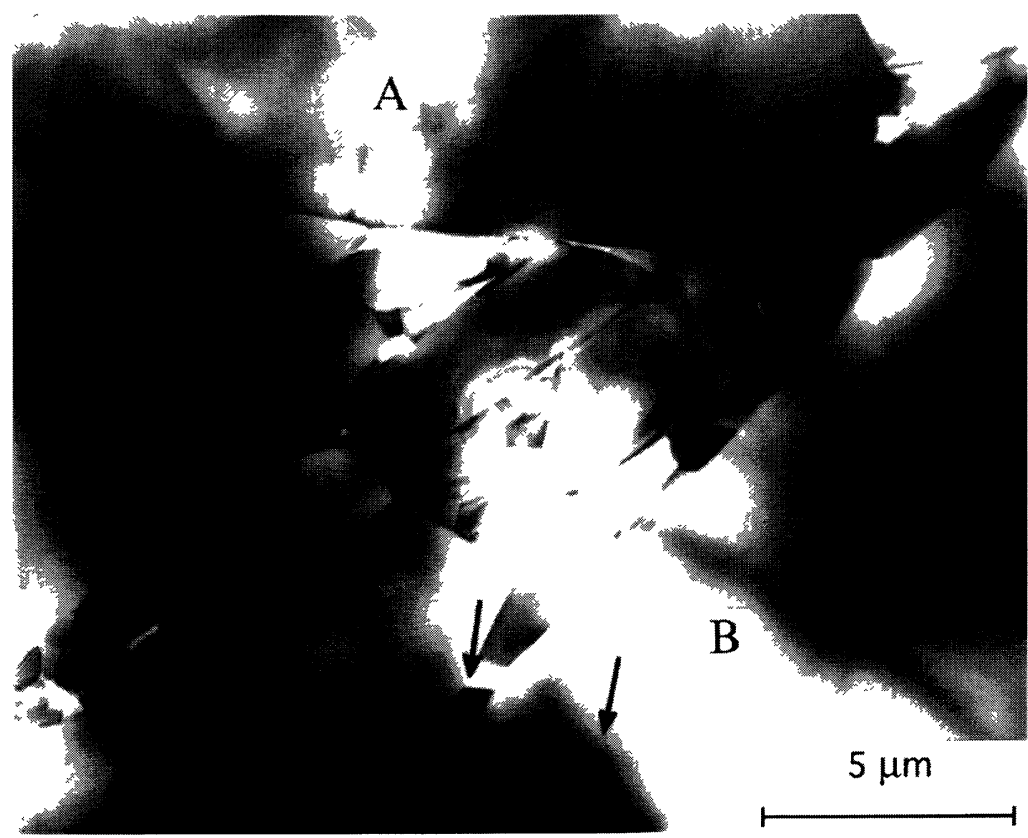

Fig. 2. - Heterogeneous microstructure of alumina "BYR". Most of the grains are lathlike shaped; some of them (A and $\mathrm{B}$ ) have undergone an exaggerated growth. They are bordered by two nearly straight parallel GB's. Only one is visible on the figure. Precipitates of yttrium aluminum garnet $\mathrm{Y}_{3} \mathrm{Al}_{5} \mathrm{O}_{12}$ (arrowed) occur at GB's and inside the grains.

unambiguously determined (misorientation $76^{\circ}[12 \overline{3} 1]$ ), has been found free of yttrium.

- two near coincidence GB's contain a high level of segregation, a Low Angle GB and a GB close to the near coincidence orientation $\Sigma=13 \mathrm{~b}\left(\Delta \theta=3^{\circ}\right.$, misorientation $92^{\circ}$ [7703], curved GB plane). These two GB's contain dislocation networks.

Consequently, these first results question the role of the three dimensional coincidence on the level of intergranular segregated species in alumina. Furthermore, the two near coincidence GB's belong to the deformed sample and contain dislocation networks; this suggests a role of intergranular dislocations on the presence of yttrium.

As a matter of fact, yttrium segregation on intergranular dislocations has been evidenced in two cases.

It has been mentioned that only one "general" GB did not contain yttrium. However, this GB contains two isolated dislocations. On these dislocations, yttrium has been detected with the STEM VG-FEG microscope as shown in figure 4.

Furthermore, a variation of yttrium content occurs along a same GB which presents a pseudoperiodic network of dislocations in its right part (Fig. 5). In this part of the GB, the yttrium concentration is one third higher than its concentration in the GB left part which contains no dislocations.

Finally a relationship between the $G B$ plane orientation and the nature of the major segregated element has been found.

Figure 6 presents several EDXS spectra obtained on different GB's in two regions of the "BYR" alumina which contain cosegregation of $\mathrm{Si}$ and $\mathrm{Y}$ (Fig. 3). The preponderance of one of these two elements in the GB is clearly related to the orientation of the GB plane. The results concerning 

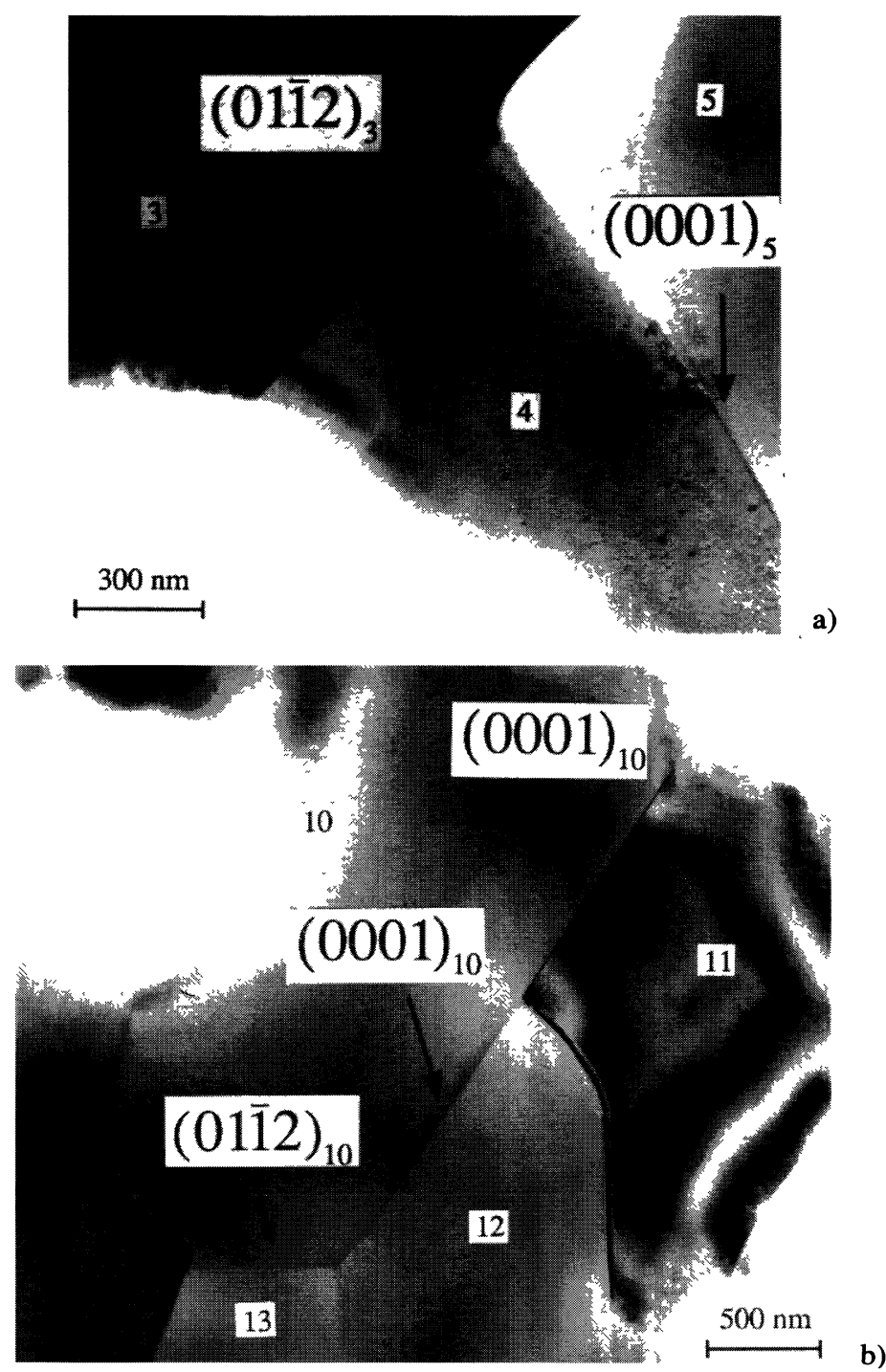

a)

Fig. 3. - Characteristic GB planes in alumina "BYR". Straight GB planes (arrowed) are parallel to dense planes $(0001)$ or $(01 \overline{1} 2)$ of alumina in one grain. The GB's between numbered crystals have been analysed i.e. $3 / 4$ and $4 / 5$ in figure $3 a$ and $10 / 11,10 / 12,10 / 13$ in figure $3 b$; the corresponding EDXS spectra are reported in figure 6.

these GB's are reported in table II and can be summarized as follows:

- the silicon content is higher than yttrium content in the GB's of plane parallel to the basal (0001) plane in one grain. HREM images reveal the presence of a vitreous phase along these GB's that are strongly faceted at the atomic level (Fig. 7). This intergranular structure is complex and the width of the amorphous phase seems to vary along the GB.

- the GB's whose plane is different from the basal plane contain a level of yttrium always higher than the level of silicon.

- the highest yttrium segregation level is obtained when the GB plane is parallel to the rhom- 


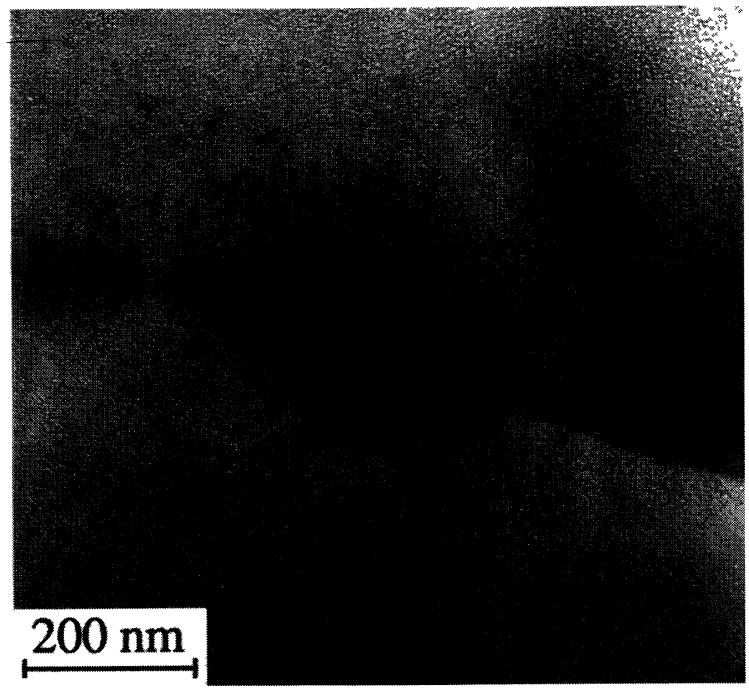

a)

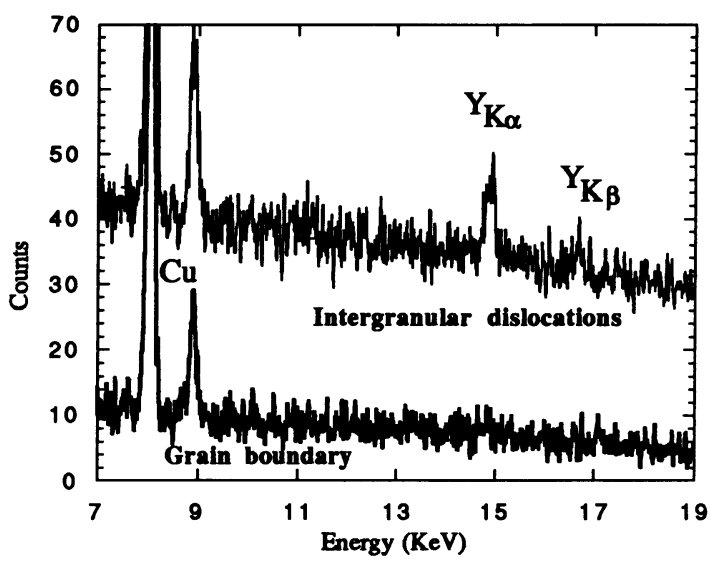

b)

Fig. 4. - Detection of yttrium on intergranular dislocations. a) Bright field image of a general GB containing 2 isolated dislocations. b) EDXS spectra obtained on two regions of the GB: yttrium is only detected on the dislocations.

bohedral plane $(01 \overline{1} 2)$ in one grain. In that case, the GB's are straight and HREM images show a periodic intergranular structure (Fig. 8).

\section{Discussion.}

Our experimental research of the structural parameters determinant for the intergranular segregation in polycrystalline alumina brings up two main important results: first there is a relationship between the orientation of the GB plane and the nature of the major segregated element; then it appears clearly that yttrium segregation is linked in some cases to the presence of extrinsic dislocations.

Let us recall that YTTRIUM is detected in nearly all GB's, as already observed in fine grained alumina [11]. Its level is generally higher than the silicon level in the alumina "BYR" containing 


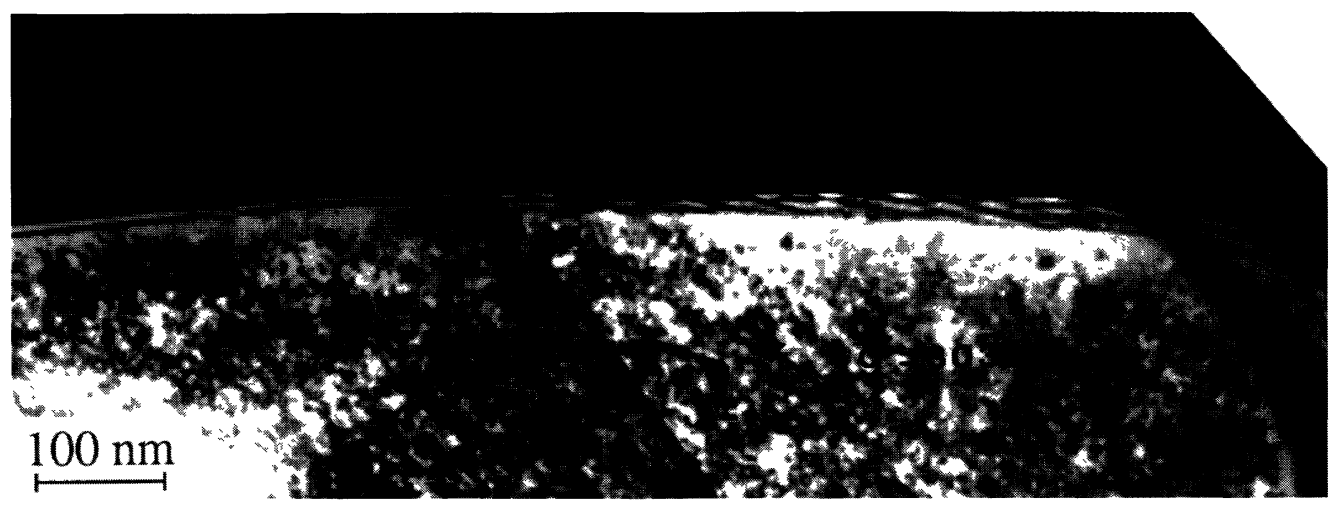

Fig. 5. - Dark field image of a general GB in the deformed sample "CMgY" (misorientation $\theta=51^{\circ}$ [11 $\overline{19} 81]$ ). A pseudo-periodic dislocation network occurs in the right part of the GB.

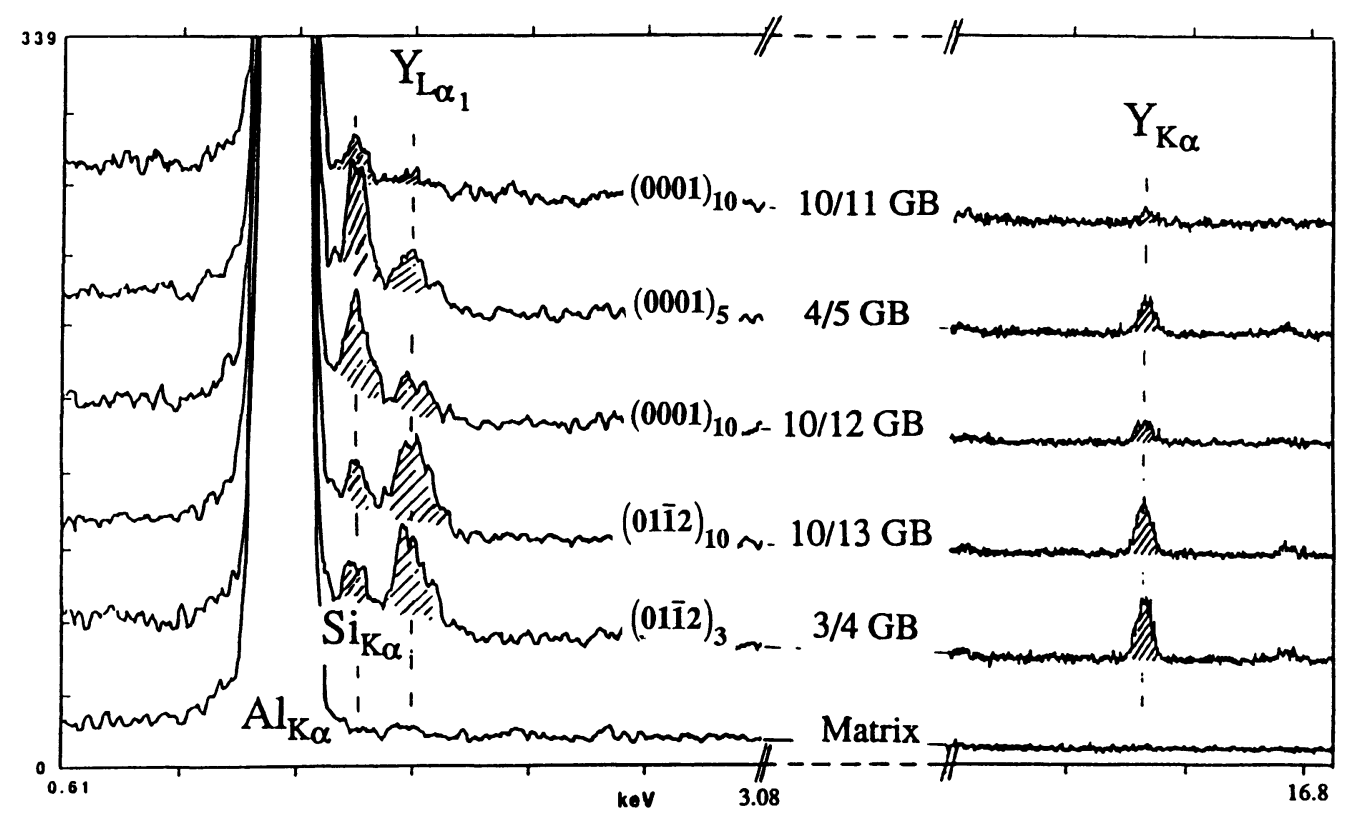

Fig. 6. - EDXS spectra obtained on several GB's of the sample "BYR". For silicon rich GB's 10/11,10/12 and $4 / 5$, the GB plane is parallel to the basal plane (0001) in one grain. For yttrium rich GB's $3 / 4$ and 10/13, the GB is parallel to the rhombohedral plane $(01 \overline{1} 2)$.

$260 \mathrm{ppm}$ of silicon. This is in agreement with a driving force for segregation resulting from solute misfit strain energy, the ionic radius of yttrium $(r=0,093 \mathrm{~nm})$ being larger than that of aluminium $(r=0,05 \mathrm{~nm})$, which is itself larger than that of silicon $(r=0,041 \mathrm{~nm})$. This segregation behavior has been evidenced in aluminas for which GB's were undoubtedly free of glassy phase [1]. Yttrium is preferentially and strongly segregated at GB's whose plane is parallel to the rhombohedral plane $(01 \overline{1} 2)$ in one grain. This plane is one of the densest planes in alumina and is often encountered as 
Table II. - Silicon and yttrium contents and crystallographic parameters of five GB's in the annealed sample "BYR".

\begin{tabular}{|c|c|c|c|c|}
\hline $\begin{array}{c}\text { Grain } \\
\text { Boundary }\end{array}$ & $\begin{array}{c}\text { SiK } / \mathbf{A l}_{\mathbf{K}} \\
\mathbf{x} 100 \\
\end{array}$ & $\begin{array}{c}Y_{L} / A_{1} I_{K} \\
\times 100 \\
\end{array}$ & $\begin{array}{c}\text { Misorien- } \\
\text { tation }\end{array}$ & GB plane \\
\hline $3 / 4$ (fig $3 b$ ) & 1.5 & 2.7 & $90^{\circ}\left[\begin{array}{llll}5 & 5 & \overline{10} & 3\end{array}\right]$ & $(0112)$ in grain 3 \\
\hline $10 / 13$ (fig $3 a)$ & 1.2 & 2.5 & & $(01 \overline{1} 2)$ in grain 10 \\
\hline $10 / 11$ (fig $3 a$ ) & 1.4 & 0.2 & $40^{\circ}\left[\begin{array}{llll}5 & 5 & \overline{10} & 2\end{array}\right]$ & $(0001)$ in grain 10 \\
\hline $10 / 12$ (fig $3 a$ ) & 3.7 & 1.7 & $41^{\circ}\left[\begin{array}{llll}5 & 1 & 4 & 1\end{array}\right]$ & $(0001)$ in grain 10 \\
\hline $4 / 5$ (fig $3 b)$ & 4.6 & 1.7 & 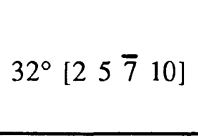 & $\begin{array}{c}(0001) \text { in grain } 5, \\
\text { at } 12^{\circ} \text { from }(0001) \\
\text { in grain } 4\end{array}$ \\
\hline
\end{tabular}

GB plane in coarse grains aluminas as well as (0001), (11 $\overline{2} 0),(\overline{1} 2 \overline{1} 3)$ and $(10 \overline{1} 0)$ planes. All these planes show high packing densities [22], the aluminium density being the highest for the (011̄2) plane. Theoretical calculations of heat of segregation of $\mathrm{Y}^{3+}$ only exist for surface segregation phenomena. They must be considered with caution in so far as GB segregation is concerned, but an interesting point is that they predict large reductions in surface energy for $(01 \overline{1} 2)$ and $(01 \overline{1} 0)$ surfaces and virtually no change for the (0001) surface. Moreover, for (01) 12 ) plane, a minimum in $\Delta H$ value exists corresponding to approximately one half coverage; this suggests the formation of a coherent second phase at these surfaces [23]. Although calculations are made for surfaces, they are in agreement with the present observations of a well ordered yttrium rich (0112) GB.

A preferential segregation of SILICON occurs on the basal (0001) plane. This has recently been observed in an alumina different from the present work alumina in microstructure and composition, in particular with a smaller grain size; in that case the GB's did not contain an amorphous phase [24]. In our large grain material, HREM images reveal the presence of an amorphous film. It is obvious that the level of segregation is a function of the grain size. Thus, it appears that the formation of a basal type GB plane, limiting the large plate-like grains that abnormally develop in non Mg-doped aluminas, could result from a segregation of silicon rather than from the presence of a vitreous film as it was often suggested. An increase in the silicon content would then lead to an increase in silicon GB concentration beyond a monolayer resulting in the formation of an amorphous film. In the case of liquid phase sintered aluminas, an explanation for the dominance of basal GB planes was proposed on the basis of experiments of reactions of a glass with different alumina surfaces. It was shown that the basal plane reacts slowly in comparison with other planes that tend to dissolve rather well in presence of anorthite [25].

It is worthnoting that in the two cases the particular behavior of the (0001) plane could result from an epitaxial growth of $\mathrm{a} \mathrm{SiO}_{2}$ containing compound; as a matter of fact, it has been suggested from diffraction experiments that the thin intergranular layer may possess some short-range order governed by the structure of the grains $[26,27]$. Work is now in progress to substantiate this hypothesis.

In fact, this GB plane dependent competition between segregated species is related to the elastic interaction in metals while the concentration of aliovalent solutes at ceramic GB's is complicated by space charge effects [28]. Indeed, the hypothesis of a strain misfit energy as a unique driving force for segregation is at variance with both segregation energy calculations and experiments in cubic ionic crystals [29]. The calculations predict that both solute and compensating defects are enhanced on the boundary plane, and a high level of segregation is measured in magnesia for elements with a negligible elastic interaction. It is thus not surprising that silicon, which 


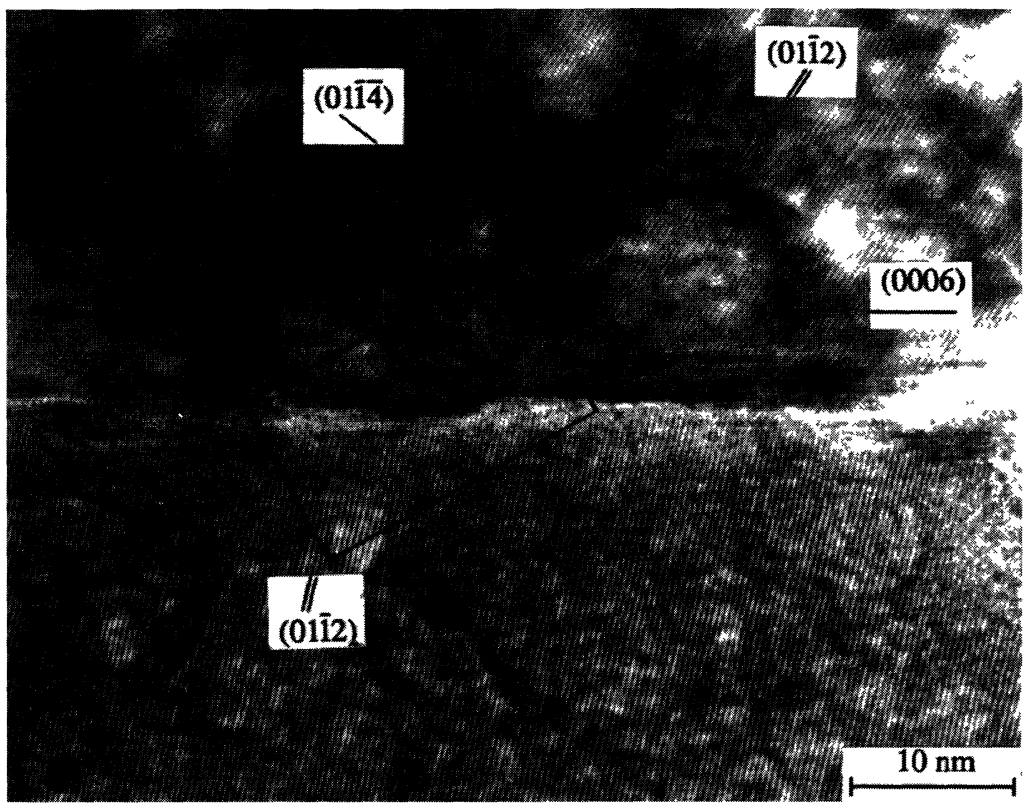

a)

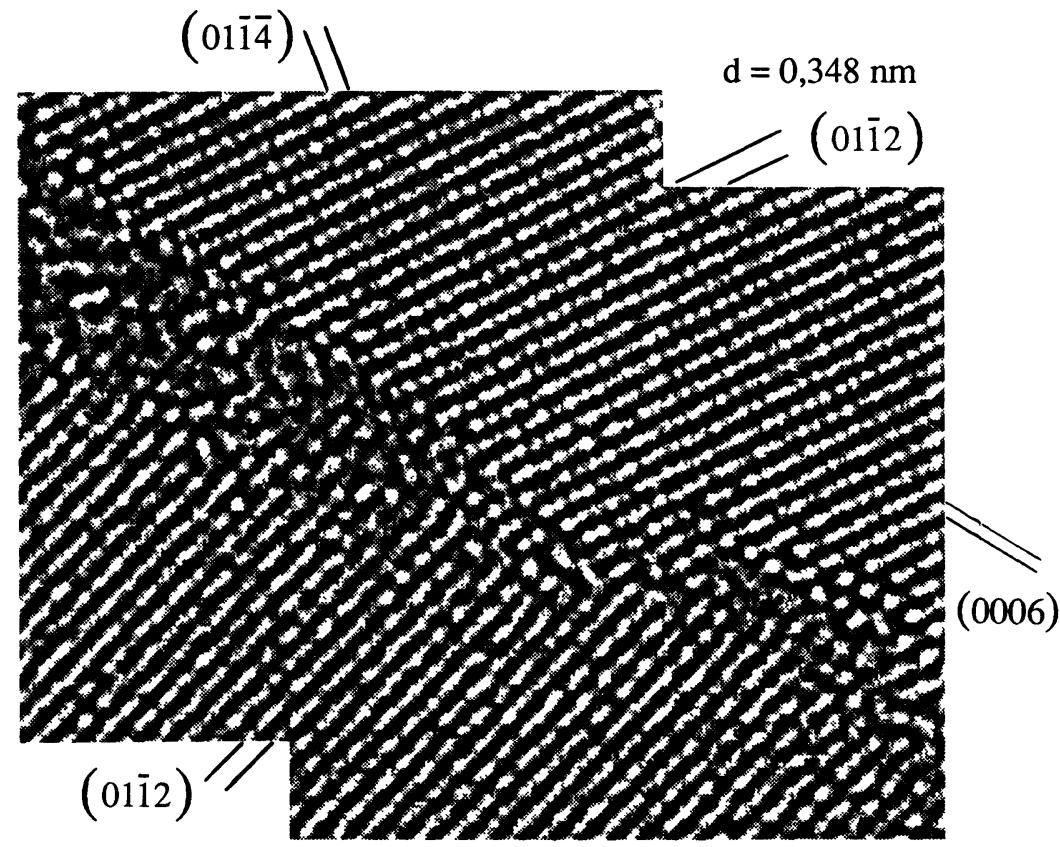

b)

Fig. 7. - HREM image of the GB 10/11 (cf. Tab. II) with basal type GB plane: image (b) corresponds to an enlargement of the highlighted region of image (a). The repartition of the silicon rich amorphous phase appears heterogeneous and the GB is faceted.

is an aliovalent solute in alumina, is encountered in some particular GB plane.

The basal plane is strongly faceted at the atomic level (Fig. 7). This is in agreement with previ- 


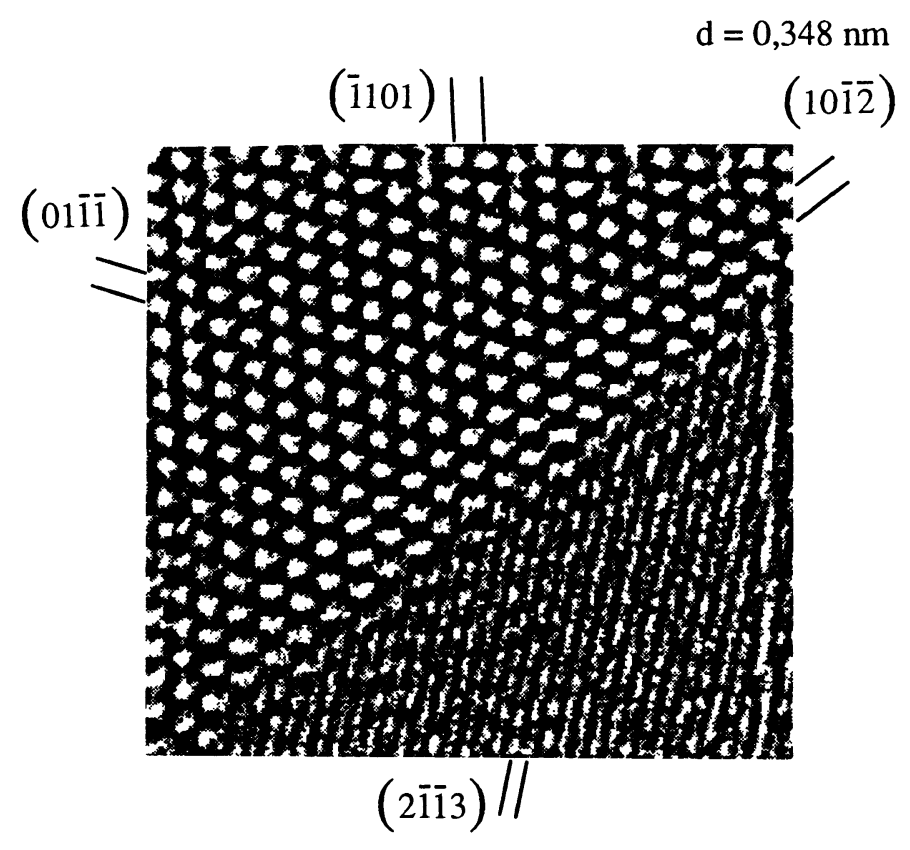

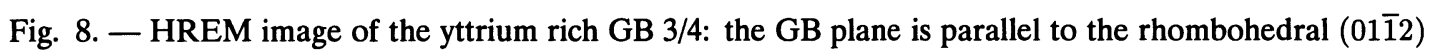
plane in one grain. The interface is rectilinear and displays an ordered structure.

ous microstructural studies where the presence of a thin intergranular layer of siliceous material caused faceting [22]. The width of the film was approximately $3 \mathrm{~nm}$. In a recent study on the structure of GB's prepared with and without a thin intergranular film, obtained by $\mathrm{SiO}_{2}$ deposition, the $\mathrm{SiO}_{2}$ enriched GB's are more strongly faceted along the (0001) plane when compared to clean interfaces [30]. Moreover, the structured, silicon rich GB's without amorphous film are atomically flat in HREM images [24], confirming that microfaceting occurs in presence of a glassy phase.

The intrinsic GB structure governed by the GB plane is obviously not the only factor which influences segregation, and we have to take into account the occurrence of extrinsic defects. The absence of yttrium in the general GB can be understood considering one of the more striking experimental evidence of our study which is the preferential segregation of YTTRIUM on intergranular dislocations, either pseudo periodically arranged or isolated. In this last case, which occurs in the general GB, it is assumed that yttrium has been attracted by the strain field of dislocations that are then stabilized by segregated species. This result justifies the proposed strengthening mechanisms that accounts for the modification of the fine-grained alumina superplastic behavior when yttrium is added [17,18]. Indeed, dislocations are present in general GB's after creep in agreement with the assumption of lower GB diffusion that results in a decrease in GB dislocation accommodation processes. Otherwise, the occurrence of extended basal stacking faults bordered by partial dislocations can only be explained if yttrium is segregated on faults and dislocations.

\section{Conclusion.}

The purpose of this work was to study by TEM (CTEM and EDXS) the relationship between intergranular segregation and structure in polycrystalline alumina: one is doped with magnesium 
and yttrium, the other one is only doped with yttrium. In order to precise this relation we have undertaken HREM on some well oriented GB's.

The main results are :

1) a strong segregation of yttrium occurs at all GB's except one in the two materials. The extent of solute segregation does not seem to depend on 3-dimensional coincidence, but is rather sensitive to the orientation of the GB plane. Otherwise, it is enhanced in presence of defects such as intergranular dislocations. The highest level of yttrium segregation is observed in GB's whose plane is parallel in one grain to the rhombohedral (01/2) plane, one of the densest plane in alumina. These yttrium-rich GB's are well ordered and flat at the atomic level as observed in HREM images.

2) the preferential segregation of yttrium on extrinsic dislocations is one of the more interesting result of the study. It confirms the hypothesis that a decrease in superplastic creep of alumina comes from a decrease in dislocation mobility and thus dislocation accommodation at GB's, resulting in higher stress concentrations as observed by TEM.

3) a segregation of silicon occurs at GB's of the annealed sample and is particularly high in GB's whose plane is of basal type in one grain. These GB's are strongly faceted in the presence of an amorphous film.

\section{References}

[1] LI C.W. and KINGERY W.D., in Ad. in Ceramics 10, Ed. by W.D. Kingery (1985) 368.

[2] BAIK S. and MOON J.H., J. of Amer. Cer. Soc., 74 (1991) 819.

[3] PAIDAR V., GeMPerlova J., LeJCEK P. and ViteK V., J. Mater. Sci. Eng., A154, (1992) 113.

[4] BollmanN W., Crystals Defects and Crystalline Interfaces, (Springer Verlag N.Y, Berlin, 1970).

[5] BOUCHET D. and PRIESTER L., Scripta Metall. 21 (1987) 475.

[6] BRANDON D.G., Acta Metall. 14 (1966) 1479.

[7] Lartigue S. and Priester L., J. Am. Cer. Soc., 71 (1988) 430.

[8] Grimmer H., Bonnet R., Lartigue S. and Priester L., Phil. Mag. A61 (1990) 493.

[9] BOUCHET D. and ThiBAULt J., Microsc., Microanal., Microstruct., 3 (1992) 1-13.

[10] Roshro A. and Kingery W.D., Com. Am. Cer. Soc., 68 (1985) C331.

[11] GRufFel P. and CARRY C., J. Europ. Cer. Soc., 11 (1993) 189.

[12] CARRY C. and MOCELlin A., Ceram. Inter, 13 (1987) 89.

[13] GRUfFEL P. and CARRY C., Proceedings of the 11th RISO international Conference on material science, Ed. J.J. Bentzen et al. (1990) 305.

[14] CANNON R.M., RHODES W.H. and HEUER A.H., J. Am. Cer. Soc., 63 (1980) 46.

[15] Heuer A.H., Tighe J.N. and CANNON R.M., J. Am. Cer. Soc., 63 (1980) 53.

[16] Priester L. and LaRTigue S., J. Europ. Cer. Soc., 8 (1991) 47.

[17] Lartigue S., CARry C. and PRIESTER L., J. Phys., C1-51 (1990) 985.

[18] LARTIGUE-KORINEK S. and DUPAU F., Acta Metall. Mater. 42 (1994) 293.

[19] Heuer A.H. and Castaing J., Advances in Ceramics, Ed. W.D. Kingery, Am. Cer. Soc. (1985) 238.

[20] CaWley J.D. and Halloran J.W., J. Am. Cer. Soc., 69 (1986) C195.

[21] Song H. and Coble R., J. Am. Cer. Soc., 73 (1990) 2077.

[22] HANSEN S.C. and PhILlips D.S., Phil. Mag A 47 (1983) 209.

[23] MACKRODT W.C., Advances in Ceramics, Ed. W.D. Kingery, 23 (1987) 293.

[24] SWIATNICKI W. and LARTIGUE-KORINEK S., private communication.

[25] SimpSON Y.K. and CARTER C.B., J. Am. Cer. Soc., 73 (1990) 2391.

[26] Clarke D.R., J. Am. Cer. Soc. 70 (1987) 15.

[27] MARION J.E., HsueH C.H. and Evans A.G., J. Am. Cer. Soc., 70 (1987) 708.

[28] DuFfy D.M. and TASKER P.W., Phil. Mag. A 50 (1984) 155.

[29] KINGERY W.D., Solid State Ionics, 12 (1984) 299.

[30] SUSNITZKY D.W. and CARTER C.B., J. Am. Cer. Soc., 73 (1990) 2485. 